\title{
Manuel GURRÍA DI BELLA, Lecciones de ética ambiental, México: Universidad de las Américas 2007, 159 pp.
}

\section{La urgencia de una reflexión medioambiental}

Los problemas medioambientales han obligado a todas las disciplinas humanas a elaborar una seria reflexión que ayude a entender desde su propio ámbito cómo es que se produjo este fenómeno y cuáles son los posibles caminos que pueden conducir a una solución. El trabajo universitario interdisciplinar no ha sido ajeno a este hecho y vemos cómo poco a poco la bibliografía relacionada con ese tema va en aumento. Muestra de ello es el libro Lecciones de ética ambiental escrito por Manuel Gurría Di Bella, profesor emérito de la Universidad de las Américas - misma que se ha encargado de su publicación -, en el que haciendo uso de sus conocimientos en administración turística y pedagogía, y relacionando éstos con una reflexión ética, nos conduce de manera muy didáctica a tomar conciencia de los elementos sustanciales que componen a nuestro planeta y a nuestra especie, la relación entre sociedad y medio ambiente, el binomio ciencia-tecnología y su aplicación en el ámbito agroindustrial, el poder de autoconservación de la naturaleza a pesar de sus amenazantes fuerzas destructoras, el compromiso político actual de educar a sus ciudadanos en temas ambientales $\mathrm{y}$, por último, las condiciones y los riesgos para el medio ambiente del turismo sostenible.

El maestro Gurría resalta la urgente necesidad de que se establezcan patrones de comportamiento morales hacia la naturaleza, los cuales en décadas pasadas no eran explícitos y, por ende, practicados, ya que los seres humanos en su afán de progreso rompieron con el orden natural o, en otras palabras, no respetaron las normas que rigen a la naturaleza ocasionando un desajuste. El resultado de esa falta de respeto moral hacia la naturaleza ha puesto a la humanidad frente a diversos problemas ambientales que van desde la escasez de agua potable, la extinción de miles de especies, la 
deforestación y desertificación de los suelos, contaminación atmosférica, acumulación de desechos sólidos, etcétera, hasta el resultado más grave y amenazante: el calentamiento gradual del planeta. Esta situación, dice el maestro Gurría, «conduce a enlazar los actos del hombre, qué son el objeto de la ética, con la conservación de su hábitat, que es un objeto de la ecología» (p. 12).

Sin lugar a dudas debe reconocerse que uno de los principales potencializadores del calentamiento global son los energéticos que utilizamos: de ahí que Gurría señale las desventajas de las fuentes tradicionales y las ventajas del uso de nuevas energías limpias. El uso que se haga de éstas debe estar marcado ya por un significado moral, debido a que su administración racional implica un sentido de justicia ambiental y social. Esto último obliga entonces a elaborar una reflexión ética y axiológica que nos lleve a un uso más racional, mediado por la voluntad y libertad, de tal manera que seamos más concientes y responsables en nuestras prácticas cotidianas.

Aunque se le ha querido dar un sentido geológico al gradual calentamiento de nuestro planeta, sabemos que éste ha sido provocado por nuestra especie a consecuencia de que hemos olvidado qué somos. Antes que burgueses tecnócratas, somos seres físicos, seres psíquicos, seres morales y seres sociales, por ello mismo Gurría se encarga de recordarnos nuestra naturaleza olvidada.

Otro aspecto importante que se considera en esta obra es el relacionado con la sobrepoblación humana. Mientras que el hombre se reproduce desaforadamente, las poblaciones animales no crecen tan rápidamente, ya que la misma naturaleza pone resistencia a su crecimiento desmedido mediante un fenómeno llamado «resistencia ambiental». Por su parte, el ser humano tiene un poder tan desarrollado de adaptación que éste, aunado a la tecnología le ha permitido sobrevivir en casi cualquier ecosistema, hace que el crecimiento de las poblaciones humanas jamás haya sido controlado de manera conciente y en la actualidad se convierta en una amenaza para la sustentabilidad.

Manuel Gurría sostiene que la tecnología y la ciencia nos han facilitado la vida, pero estos poderes pueden utilizarse de modo positivo o negativo. Positivamente, nos han hecho más fácil la transformación de la naturaleza, pero se ha abusado en grado ex- 
tremo de estos poderes y esto ha dado como resultado la contaminación agrícola por la invención y uso indiscriminado de pesticidas y fertilizantes, la contaminación atmosférica y urbana por el uso de transportes, etcétera. Y en la práctica cotidiana, la ciencia y la tecnología nos han hechos seres esclavizados al confort, a los celulares, al Internet, nos han desfasado de la naturaleza, hemos creado un Hinterwelt, un mundo detrás del mundo real, del mundo natural, un mundo esclavo de los aparatos electrónicos que tanto daño hacen al medio ambiente.

Los cambios climáticos han estado presentes desde su origen en nuestro planeta, sin embargo, Gurría Di Bella nos obliga a tomar conciencia de que muchos de los cambios actuales son producto de las acciones humanas, por lo tanto es indispensable que los gobiernos se responsabilicen a crear legislaciones y políticas ambientales acordes con las necesidades propias de su comunidad y de su ecosistema.

En la parte final del libro el autor, en absoluta congruencia con su formación académica, explica los peligros y las oportunidades que ofrecen, respectivamente, la actividad turística tradicional - basada en la explotación irrestricta, depredadora y contaminadora de los ecosistemas con fines meramente lucrativos - frente al ecoturismo cuyo objetivo es repestar, proteger y conservar la naturaleza.

Victor Hugo Salazar Ortiz

Departamento de Filosofía Universidad Autonoma de Aguascalientes 